\title{
Kriptokokkoz için risk faktörü olarak Alanya şehir merkezinde Cryptococcus neoformans kolonizasyonunun ilk izolasyonu
}

\author{
First isolation of Cryptococcus neoformans colonization in Alanya city center as a \\ risk factor for cryptococcosis
}

Mete Tunahan Peker, Çağrı Ergin

\section{Öz}

Amaç: Bağışıklığı baskılanmış insanlarda ve hayvanlarda yaşamı tehdit eden enfeksiyonlara neden olabilen Cryptococcus neoformans ve Cryptococcus gattii, çevresel odaklardan hassas olan konağa bulaşır. Patojen biyoklimatik değişkenlere uygun şekilde çevresel kolonizasyon gösterir. Daha önceki MaxEnt makine öğrenmesi ile yapılan analizlerde, Alanya bölgesi muhtemel kolonizasyon bölgesi olarak saptanmıştır. Bu çalışmanın amacı, ülkemiz için önemli bir turizm bölgesi olan Alanya ve yakın çevresindeki kovuklu ağaç florasında C. neoformans ve $C$. gattii kolonizasyonunun araştırılmasıdır.

Gereç ve yöntem: Alanya şehir merkezi ve yakınındaki Dim çayı çevresinden, üzerinde geniş kovuk olduğu belirlenen 49 zeytin (Olea europea), 17 keçiboynuzu (Ceratonia siliqua) ve 13 okaliptüs (Eucalyptus camaldulensis) olmak üzere toplam 79 ağaçtan standart eküvyon yöntemi ile örnekleme yapıldı. Bifenil ve kloramfenikol içeren Staib agar kültür için kullanıldı. Üreyen maya benzeri, kahverengi pigmentli koloniler konvansiyonel yöntemler ve kanavanin-glisin-bromtimol agar reaksiyonu ile tanımlandı.

Bulgular: Alanya şehir merkezinde sadece bir $(\% 2,04)$ zeytin (O. europea) ağacında C. neoformans kolonizasyonu saptandı.

Sonuç: Bu çalışmada, C. neoformans'ın Türkiye'nin önemli turizm kenti olan Alanya şehir merkezinden izole ettiği ilk çevresel kolonizasyonu rapor edilmiştir. Çevresel insan patojenik mantarlarının kolonizasyonu için ülkemizin insan yerleşimlerinin ve turizm potansiyeli yüksek bölgelerinin sistematik olarak taranması riskli alanların bulunmasına yardımcı olacaktır.

Anahtar kelimeler: Cryptococcus neoformans, çevresel, Alanya, Olea europea.

Peker MT, Ergin Ç. Kriptokokkoz için risk faktörü olarak Alanya şehir merkezinde Cryptococcus neoformans kolonizasyonunun ilk izolasyonu. Pam Tıp Derg 2022;15:23-28.

\section{Abstract}

Purpose: Cryptococcus neoformans and Cryptococcus gattii, which can cause life-threatening infections in immunocompromised humans and animals, is spreading from environmental niches to the susceptible host. It shows environmental colonization in accordance with pathogen bioclimatic variables. In the previous analyzes made with MaxEnt machine learning, the possible colonization area of Alanya region was determined. The aim of this study is to screen the colonization of $C$. neoformans and $C$. gattii in the hollow trees of Alanya and its nearby Dim River, which is an important tourism region for our country.

Materials and methods: Standard swabbing technique was used for sampling from 79 trees in total as 49 olives (Olea europea), 17 carob (Ceratonia siliqua) and 13 eucalyptus (Eucalyptus camaldulensis), which were determined to have large hollows on the city center of Alanya and around the Dim River. Staib agar (supplemented with biphenyl and chloramphenicol) were used for cultivation period. Yeast-like, brown pigmented colonies were identified with conventional methods and canavanine-glycine-bromtimol agar reactions.

Results: Only one (2.04\%) olive (O. europea) tree resulted colonized by $C$. neoformans at the city center of Alanya.

Conclusion: In this study, the first environmental colonization of $C$. neoformans isolate from Alanya city center as significant tourism center of Turkey, was reported. Systematic screening of human settlements and regions of our country with high tourism potential for the presence of colonization of environmental human pathogenic fungi will help to find risky areas.

Key words: Cryptococcus neoformans, environmental, Alanya, Olea europea.

Peker MT, Ergin C. First isolation of Cryptococcus neoformans colonization in Alanya city center as a risk factor for cryptococcosis. Pam Med J 2022;15:23-28.

Mete Tunahan Peker, Dr. Pamukkale Üniversitesi, Tıp Fakültesi, Özel Çalışma Modülü Programı, Denizli, Türkiye, e-posta: mpeker171@posta. pau.edu.tr (https://orcid.org/0000-0003-1402-7936)

Çărı Ergin, Prof. Dr. Pamukkale Üniversitesi, Tıp Fakültesi, Tıbbi Mikrobiyoloji Anabilim Dalı, Denizli, Türkiye, e-posta: cagri@pau.edu.tr (https://orcid.org/0000-0001-7783-8723) (Sorumlu Yazar) 


\section{Giriş}

Cryptococcus neoformans çoğunlukla bağışıklığı baskılanmış konakta hayatı tehdit eden enfeksiyonlara neden olabilen bazidiyomiçet maya mantarıdır. Ülkemizin farkı bölgelerinden pnömoni ve menenjit olguları rapor edilmiş, menenjit için 0,13/100.000 oranında, ciddi klinik tablo oluşturabilecek enfeksiyon hızı hesaplanmıştır [1, 2]. Aynı genus içinde bulunan diğer insan ve hayvan patojeni Cryptococcus gattii ile infeksiyon ise henüz ülkemizden bildirilmemiştir. Ülkemizde 1974 yılından itibaren farklı çevresel odaklardan ve farklı doğal ortamlarda $C$. neoformans kolonizasyonu bildirilmektedir [3-8]. Kolonize olduğu çevresel ortamlardaki basidiyosporları veya virülan haldeki kuru yapısı ile maya, solunum havasına karışarak konağa bulaşır [9].

Mayanın çevresel kolonizasyonunda ağaç ortam seçiciliği yoktur, çok farklı ağaç türleri üzerinde kolonize olarak eşeyli formda yaşam döngüsünü devam ettirebilir [10]. Kolonize olduğu çevresel ortamdaki özgün fungal mikrobiyomun da bu kolonizasyonda etken olduğu öne sürülmüştür [9]. Dış ortamda canlı kalabilmesinde etken olan faktörler (sıcaklık, bağıl nem, $\mathrm{pH} v b$ ) mayanın virülansını doğrudan etkilemektedir. Mayanın canlılar arasında doğrudan geçişi çok nadirken, enfekte canlıdan tekrar doğaya karışması, oraya uyum sağlayarak çoğalması ve basidiyosporlarının oluşarak konağa bulaşması ile doğadaki döngüsü tamamlanır [9, 11].

Ülkemizde çevresel kolonizasyonun yoğun olduğu bölgeler ve biyoklimatik özellikler temel alınarak yapılan öngörülerde, Alanya ve çevresi kolonizasyona uygun olarak bulunmuştur [12]. Bölgenin iklim ve ekonomi yapısına bağlı olarak nüfus yoğunluğu yüksektir [1]. Bu çalışmanın amacı, nüfus yoğunluğunun yüksek olduğu Alanya şehir merkezinde ve turizm faaliyetlerinin bulunduğu ve vadi yapısında olan Dim çayı çevresinde insan patojeni $C$. neoformans ve $C$. gattii'nin araştırılmasıdır.

\section{Gereç ve yöntem}

Araştırmaya Alanya şehir merkezi (Şekil 1) ve Dim çayı bölgesi (Şekil 2) alındı. Bölgede üzerinde geniş kovuk bulunan ağaçların varlığı araştırıldı. Örnekleme yapılan noktaların coğrafi koordinatları kişisel cep telefonu ile kaydedildi. Alanya şehir merkezinde üzerinde kovuk bulunan 40 zeytin (Olea europea) ve Dim çayı bölgesinde üzerinde kovuk bulunan 17 keçiboynuzu (Ceratonia siliqua), 13 okaliptüs (Eucalyptus camalduensis) ve dokuz O. europea olmak üzere toplam 79 ağaçtan örnekleme yapıldı.

Çevresel örneklerin toplanması ve işlenmesinde Randhawa ve ark. [13] tarafından önerilen yöntem uygulandı. Kısaca, içerisinde steril \%0,9 $\mathrm{NaCl}(\% 0,4$ kloramfenikol ilave edilmiş) bulunan serum fizyolojik hazırlandı. $\mathrm{Bu}$ solüsyon ile ıslatılan eküvyonun fazla sıvısı tüpün kenarından akıtıldı ve nemli eküvyon, örnekleme yapılacak ağaç kovuğunun farklı noktalarına sürtüldü. Alınan örnek, aynı solüsyon içinde bırakıldı. Oda sıcaklığında bırakılan örnekler, 48 saat içinde ekim yapılacak laboratuvara ulaştırıldı. Laboratuvarda örnekler ekilmeden önce vortekslendi ve eküyon ile kaba partiküllerin olmadığı üst yüzeyden alınan sıvı, $\% 0,4$ kloramfenikol ve \%0,5 bifenil içeren Staib agar besiyerine ekildi. Ekimler, oda ısısında, günlük kontrol edilerek 10 gün süre ile enkübe edildi. Staib agarda kahverengi pigment oluşturan, $S$ koloni yapısında koloniler Sabouraud dekstroz agar besiyerinde subkültüre edilerek saflaştırıldı ve boyalı mikroskobik incelemeye alındı. Maya morfolojisindeki mantarlar $37^{\circ} \mathrm{C}$ 'da üreme, üreaz aktivitesi, mısırunlu agar mikromorfolojisi ve kanavanin-glisin-bromtimol agar reaksiyonuna göre tanımlandı.

\section{Bulgular}

Araştırma bölgelerindeki örnekleme noktalarının coğrafi konumları GoogleEarth Pro (Ver 7.3) programına aktarılarak görselleştirildi (Şekil 1, 2). Alanya şehir merkezinde örnekleme yapılan 40 ağaçtan birinde $(\% 2,50)$ C. neoformans saptandı (Şekil 3). Dim çayı bölgesinden alınan 49 tarama örneğinde izolasyon yapılamadı. İzolasyon yapılan ağaç Alanya şehir merkezinde; 36³2'56" kuzey enlemi, $31^{\circ} 59^{\prime} 20^{\prime \prime}$ doğu boylamı koordinatlarına O. europea olarak tanımlandı. Bu çalışmada taranan bölgede izolasyon oranı $\% 1,27$ 'dir.

\section{Tartışma}

Akdeniz ülkelerinde çevresel C. neoformans ve C. gattii kolonizasyonu, insan sağlığını tehdit eden patojenin bölgesel dağılımlarını saptamak amacına yönelik olarak bir süredir incelenmektedir [3]. Geniş bir coğrafyayı kapsayan bu bölgelerdeki mayanın genotipik 


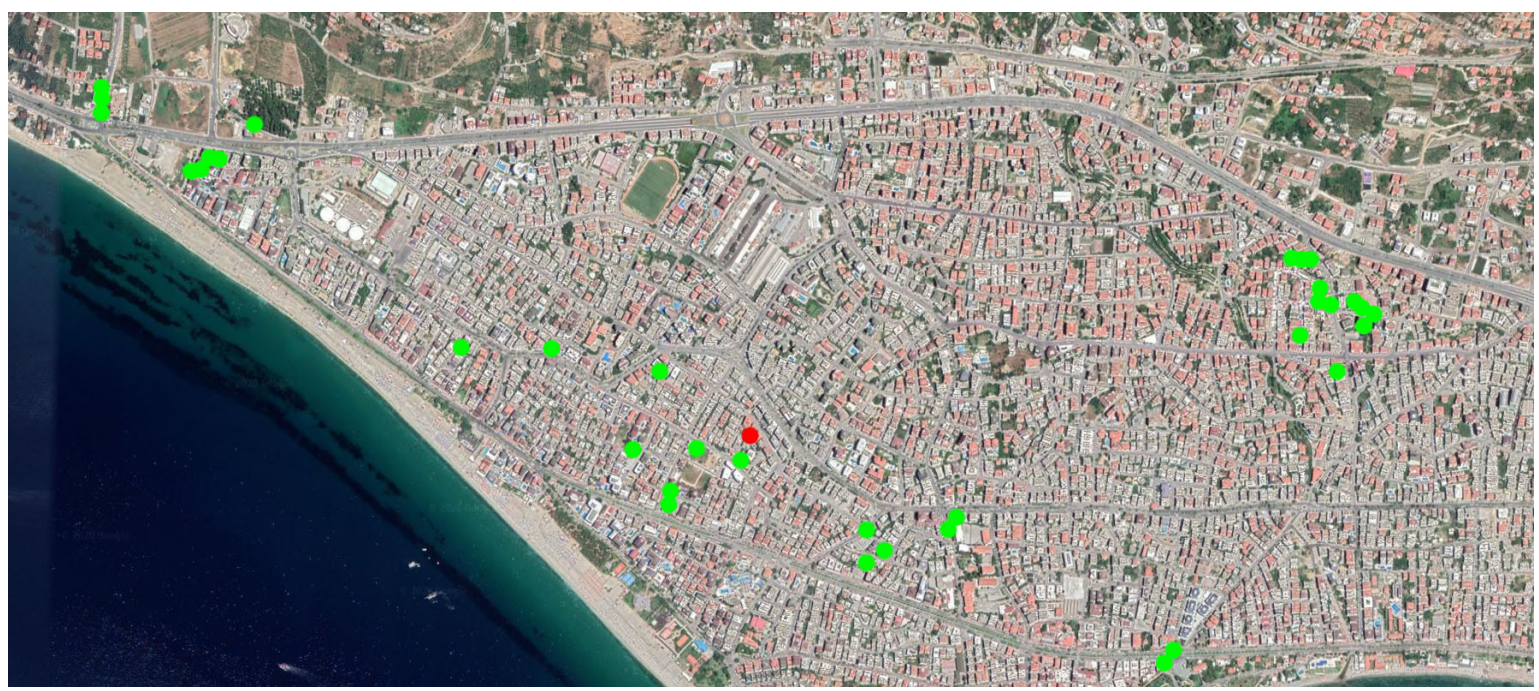

Şekil 1. Alanya şehir merkezinde örnekleme bölgesi

(Yeşil: Negatif örnekleme noktaları; Kırmızı: C. neoformans izolasyon noktası)

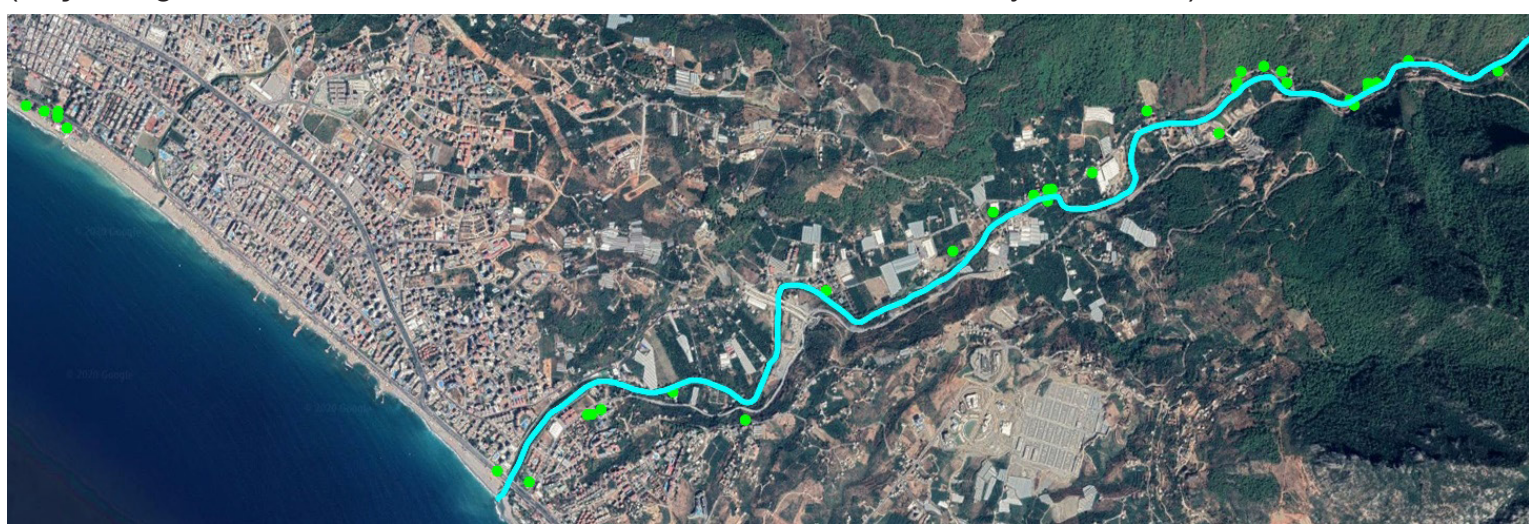

Şekil 2. Alanya Dim çayı örnekleme bölgesi

(Mavi: Dim çayı yatağı; Yeşil: Örnekleme noktaları)

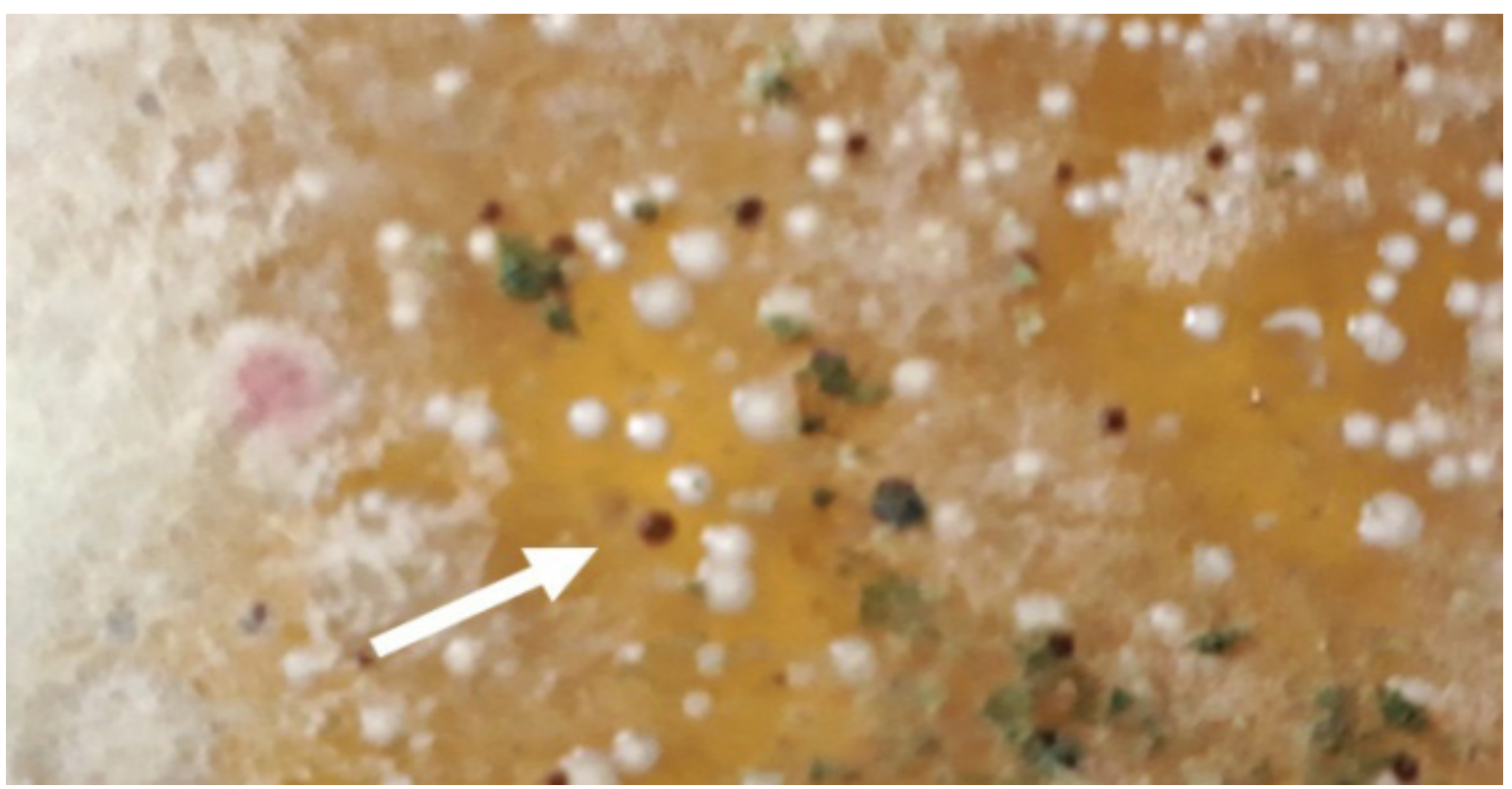

Şekil 3. Alanya şehir merkezi 16.no örneğin, Staib agar petrisinde, farklı küf kolonileri arasında 8. günde üremesi saptanan, melanin benzeri kahverengi pigment yapan Cryptococcus neoformans kolonisi (beyaz ok) 
Özellikleri, ülkemizde çevreden izole edilen kökenlerin çoğunluğunun Avrupa ile benzerlik göstermesi ile birlikte, Afrika ve Güney Amerika kökenleriyle genetik benzerlik olabildiğini de göstermiştir [6, 14]. İnsanlarda görülen enfeksiyonların çoğunlukla immünsüprese grupta bulunması, Alanya gibi özellikle nüfus yoğunluğu ve turizme bağlı insan hareketliliğinin bulunduğu bölgelerimizde çevresel patojenlerin taranmasını zorunlu hale getirmiştir.

Çevresel insan patojeni kriptokokların kolonizasyon noktalarının saptanması, uzun süre alan saha çalışmaları ile elde edilmektedir. Bu veriler coğrafi bilgi sistemlerine aktarılmaktadır. Bu veriler, yıl içindeki dönemsel nem, sıcaklık ve diğer biyoklimatik değişkenlerin analize alındığı makine öğrenmesi programları yardımı ile analize alınarak, potansiyel riskli bölgeler saptanabilmektedir. Alanya şehir merkezi ve çevresi, ülkemizdeki daha önceden yapılan çevresel kolonizasyon verilerinin kullanılması ile $C$. neoformans için riskli bölge olarak saptanmıştır. Sunulan araştırmadan elde edilen veriler, daha önceden yapılan MaxEnt makine öğrenmesi programı ile elde edilen riskli harita bölgeleri haritasının tutarlı olduğunu göstermiştir [12].

Ülkemizde Ege bölgesinde E. camaldulensis, O. europea, ılgın (Tamarix hispida), doğu çınarı (Platanus orientalis), kestane (Castanea sativa) ağaçlarında, Marmara bölgesinde ise çam ağacından kolonizasyon bildirilmiştir [37, 11, 12, 15]. Bioklimatik verilerin analizlerine göre ülkemizin farklı bölgelerinde insan patojeni kriptokokların kolonize olmasına uygun bitki örtüsü bulunmaktadır [12, 16, 17]. Tüm Akdeniz havzasının çevresinde yapılan ve kıyısı olan ülkelerde yürütülen taramalarında C. neoformans'ın kolonizasyonu için özgün bir kolonizasyon yatkınlığı olan ağaç bulunamamıştır [3, 10]. Mayanın dış ortamda yaşama kapasitesi, yapısında bulunan çevresel uyum özelliklerine bağlanmıştır.

Hilmioğlu Polat ve ark.'nın [1] çalışmasında ülkemizde yoğun nüfusun bulunmasına ve organ nakli gibi immün süpresyon oluşturan hastalıkların prevalansları gözönüne alındığında 0,13/100.000 oranında yıllık kriptokokkoz öngörüsünde bulunulmuştur. Ülkemizdeki ilk kriptokokkoz olgusu 1960 yılında bildirilmiştir [18]. Geçen sürede olgu sayıları artmıştır [1, 2]. Ülkemizde HIV infeksiyonunun artma trendinde bulunması, asemptomatik antijenemi veya semptomatik kriptokokkoz olgularının daha sık karşılaşılmasına neden olacaktır [1, 19, 20]. Çevresel kolonizasyonuna bağlı bulaşların klinisyen tarafından saptanması zordur. Ancak çevresel kolonize riskli bölgelerin saptanması, bu bölgelerde yaşayan ve/veya turizm öyküsü olan kişilerde, klinik şüphe varlığında uygun serolojik ve klinik parametrelere bağlı algoritmaların tanımlanması, tanı açısından önemlidir [20].

Sunulan araştırmanın en önemli kısıtılığı, özellikle hızlı üreyen zigomiçet küflere bağlı kültür zorluğudur. Her ne kadar bifenil hızlı üreyen çok sayıda küfü baskılayabiliyorsa da, üreyen $C$. neoformans kolonilerinin bir kısmı, filamentöz yapıların yoğunluğu (Şekil 3) nedeni ile gözden kaçabilmektedir. Örneklerin alım yerleri olan kovukların, yüksek bağıl nem ve yıl boyunca çok değişim göstermeyen sabit sıcaklık nedeni ile Rhizopus, Mucor vb gibi zigomiçet ekolojisine çok uygun olması, bu tür mantarlarında bu ortamlarda yoğun bir şekilde bulunmasına neden olmaktadır [21]. Klinik mikolojide kullanılan aktidionun Cryptococcus genusunun üremesine inhibitör etki yapması, bu araştırmada kullanılan bifenilin de yüksek konsantrasyonlarda aynı etkiyi göstermesi nedeni ile benzer şekilde yapılan araştırmalarda karşılaşılanbu sorun, bugün için kaçınılmazdır. Çözüm olarak aynı örneğin çok sayıda besiyerine ekilmesi önerilmektedir. Benomil benzeri zirai antifungallerin, bifenil yerine çevresel insan patojeni mantarların taramalarında kullanılabileceği rapor edilmişse de, henüz yaygın uygulaması yapılmamıştır [22]. Bir diğer araştırma yöntemi de, kolonizasyonun tarandığı bölgelerde amplikon tabanlı, yeni nesil dizileme teknikleri ile ortamda mayanın DNA barkodlarının araştırılmasıdır [21].

Sunulan araştırma, popülasyonun yoğun bulunduğu Alanya bölgemizde çevresel C. neoformans kolonizasyonu olduğunu göstermiştir. Sonuç olarak, bu bölgede yaşayan, turizm nedeni ile seyahat öyküsü olan ve özellikle immün sistemi baskılanmış hastalarda görülen enfeksiyonlarda, kriptokokkozun da göz önüne alınarak sorgulanması gerektiğini düşündürmektedir.

Çıkar ilişkisi: Yazarlar çıkar ilişkisi olmadığını beyan eder. 


\section{Kaynaklar}

1. Hilmioglu Polat S, Seyedmousavi S, Ilkit M, et al. Estimated burden of serious human fungal diseases in Turkey. Mycoses 2019;62:22-31. https://doi. org/10.1111/myc. 12842

2. Birinci A, Tanrıverdi Çaycı Y, Alakbarova G. Bir üniversite hastanesinde kriptokokkoz olguları. Turk Mikrobiyol Cemiy Derg 2016;46:188-190. https://doi. org/10.5222/TMCD.2016.188

3. Cogliati M, D'Amicis R, Zani A, et al. Environmental distribution of Cryptococcus neoformans and $C$. gattii around the Mediterranean basin. FEMS Yeast Res 2016;16:fow045. https://doi.org/10.1093/femsyr/ fow045

4. Ergin C, Ilkit M, Hilmioglu S, et al. The first isolation of Cryptococcus neoformans from Eucalyptus trees in South Aegean and Mediterranean Regions of Anatolia in Turkey despite Taurus Mountains alkalinity. Mycopathologia 2004;158:43-47. https://doi. org/10.1023/b:myco.0000038431.72591.7e

5. Ergin C, Kaleli I. Denizli şehir merkezinde kovuklu ağaç gövdelerinden Cryptococcus neoformans izolasyonu. Mikrobiyol Bul 2010;44:79-85.

6. Ergin C, Sengul M, Aksoy L, et al. Cryptococcus neoformans recovered from olive trees (Olea europaea) in Turkey reveal allopatry with African and South American lineages. Front Cell Infect Microbiol 2019;9:384. https://doi.org/10.3389/fcimb.2019.00384

7. Gökçen H, Ergin Ç. Muğla Milas ilçe yerleşimi bölgesi Eucalyptus camaldulensis ağaçlarından Cryptococcus neoformans izolasyonu. Pam Tıp Derg 2014;7:109112. https://doi.org/10.5505/ptd.2014.71676

8. Tümbay E. İzmir yöresinde Cryptococcus neoformans ve kriptokokkoz. I. Kısım. Cryptococcus neoformans'in doğal kaynaklardan izolasyonu. Tübitak VI Bilim Kongresi Tıp Araştırma Grubu Tebliğleri, Ankara. 1977:339-366.

9. Kwon Chung KJ, Fraser JA, Doering $\mathrm{TL}$, et al. Cryptococcus neoformans and Cryptococcus gattii, the etiologic agents of cryptococcosis. Cold Spring Harb Perspect Med 2014;4:a019760. https://doi. org/10.1101/cshperspect.a019760

10. Springer DJ, Mohan R, Heitman J. Plants promote mating and dispersal of the human pathogenic fungus Cryptococcus. PLoS One 2017;12:e0171695. https:// doi.org/10.1371/journal.pone.0171695

11. Maliehe M, Ntoi MA, Lahiri S, et al. Environmental factors that contribute to the maintenance of Cryptococcus neoformans pathogenesis. Microorganisms 2020;8:180. https://doi.org/10.3390/ microorganisms 8020180
12. Ergin C, Sengul M, Dogen A, Ilkit M. Türkiye genelinde Cryptococcus neoformans'ın tür dağılımının tahmini. Mikrobiyol Bul 2019;53:233-238. https://doi. org/10.5578/mb.67999

13. Randhawa HS, Kowshik T, Khan ZU. Efficacy of swabbing versus a conventional technique for isolation of Cryptococcus neoformans from decayed wood in tree trunk hollows. Med Mycol 2005;43:67-71. https:// doi.org/10.1080/13693780410001712025

14. Cogliati $M$, Desnos Ollivier M, McCormick Smith I, et al. Genotypes and population genetics of Cryptococcus neoformans and Cryptococcus gattii species complexes in Europe and the mediterranean area. Fungal Genet Biol 2019;129:16-29. https://doi. org/10.1016/j.fgb.2019.04.001

15. Cogliati M, Zani A, Rickerts V, et al. Multilocus sequence typing analysis reveals that Cryptococcus neoformans var. neoformans is a recombinant population. Fungal Genet Biol 2016;87:22-29. https://doi.org/10.1016/j. fgb.2016.01.003

16. Cogliati M, Puccianti E, Montagna MT, et al. Fundamental niche prediction of the pathogenic yeasts Cryptococcus neoformans and Cryptococcus gattii in Europe. Environ Microbiol 2017;19:4318-4325. https:// doi.org/10.1111/1462-2920.13915

17. Acheson ES, Galanis E, Bartlett K, Mak S, Klinkenberg B. Searching for clues for eighteen years: deciphering the ecological determinants of Cryptococcus gattii on Vancouver Island, British Columbia. Med Mycol 2018;56:129-144. https://doi.org/10.1093/mmy/ $\operatorname{myx} 037$

18. Unat EK, Pars B, Kosyak J. Bir kolon cryptococcosis'i vak'ası. İst Ünv Tıp Fak Mecm 1960;22:1318-1350.

19. Gokengin D, Doroudi F, Tohme J, Collins B, Madani N. HIVIAIDS: trends in the Middle East and North Africa region. Int $\mathrm{J}$ Infect Dis 2016;44:66-73. https://doi. org/10.1016/j.ijid.2015.11.008

20. Karaman E, Ilkit M, Kuscu F. Identification of Cryptococcus antigen in human immunodeficiency virus-positive Turkish patients by using the Dynamiker ${ }^{\circledR}$ lateral flow assay. Mycoses 2019;62:961-968. https:// doi.org/10.1111/myc. 12969

21. Schmertmann LJ, Irinyi L, Malik R, Powell JR, Meyer $\mathrm{W}$, Krockenberger MB. The mycobiome of Australian tree hollows in relation to the Cryptococcus gattii and $C$. neoformans species complexes. Ecol Evol 2019;9:9684-9700. https://doi.org/10.1002/ece3.5498

22. Pham CD, Ahn S, Turner LA, Wohrle R, Lockhart SR. Development and validation of benomyl birdseed agar for the isolation of Cryptococcus neoformans and Cryptococcus gattii from environmental samples. Med Mycol 2014;52:417-421. https://doi.org/10.1093/mmy/ myt028 
Etik kurul onayı: $\mathrm{Bu}$ araştırmanın içeriği, TR Dizin kapsamında "etik kurul izni gerektiren makaleler" kapsamında değerlendirilmemektedir.

\section{Yazarların makaleye olan katkıları}

M.T.P. ve Ç.E. çalışmanın ana fikrini ve hipotezinikurgulamışdır. M.T.P. teoriyigeliştirmiş, gereç ve yöntem bölümünü düzenlemiştir. Sonuçlar kısmındaki verilerin değerlendirmesini M.T.P. ve Ç.E. yapmıştır. Makalenin tartışma bölümü M.T.P. tarafından yazılmış, Ç.E. gözden geçirip gerekli düzeltmeleri yapmış ve onaylamıştır. Ayrıca tüm yazarlar çalışmanın tamamını tartışmış ve son halini onaylamıştır. 